\title{
Ethnic disparities in insulin and glucose-dependent insulinotropic peptide (GIP) responses to intraduodenal glucose in health
}

\author{
Chinmay S. Marathe · Michelle Bound • \\ Kylie Lange $\cdot$ Karen L. Jones • Christopher K. Rayner • \\ Michael Horowitz
}

Received: 12 October 2014 / Accepted: 31 October 2014/Published online: 16 November 2014

(C) The Author(s) 2014. This article is published with open access at Springerlink.com

$\begin{array}{ll}\text { Abbreviations } \\ \text { ID4 } & \text { Intraduodenal glucose infusion at } 4 \mathrm{kcal} / \mathrm{min} \\ \text { GIP } & \text { Glucose-dependent insulinotropic polypeptide } \\ \text { GLP-1 } & \text { Glucagon-like peptide-1 } \\ \text { DI } & \text { Disposition index } \\ \text { HC } & \text { Han Chinese } \\ \text { C } & \text { Caucasian }\end{array}$

East Asians appear to secrete less insulin than Caucasians following oral glucose suggesting that impaired insulin secretion is fundamental to the pathogenesis of type 2 diabetes [1]. Information about the secretion of the incretin hormones, GIP and GLP-1, dependent on duodenal glucose load [2], in East Asians is limited [3]. We have evaluated glycemic, insulinemic and incretin hormone responses to intraduodenal glucose in healthy Han Chinese.

We studied eleven Han Chinese (HC) and eight Caucasian (C) healthy men; the latter included in a previous study [2]. Each subject attended following an overnight fast. A catheter, incorporating an infusion channel opening $12 \mathrm{~cm}$ beyond the pylorus, was inserted intranasally [2].

Managed by Massimo Porta.

C. S. Marathe $(\bowtie) \cdot$ M. Bound $\cdot$ K. Lange

K. L. Jones · C. K. Rayner · M. Horowitz

Discipline of Medicine, Royal Adelaide Hospital,

University of Adelaide, Adelaide 5000, Australia

e-mail: chinmaymarathe@gmail.com

C. S. Marathe $\cdot$ M. Bound $\cdot$ K. Lange $\cdot$ K. L. Jones ·

C. K. Rayner · M. Horowitz

Centre of Research Excellence (CRE) in Translating

Nutritional Science to Good Health,

University of Adelaide, Adelaide, Australia
An IV cannula was placed in an antecubital vein. Intraduodenal (ID) glucose $(25 \mathrm{~g} / 100 \mathrm{~mL})$ was infused at $4 \mathrm{kcal} / \mathrm{min}$ from $t=0$ to $120 \mathrm{~min}$. Blood was collected at $t=0,15,30,45,60,90,105$ and $120 \mathrm{~min}$ for measurements of blood glucose, plasma insulin, GIP and GLP-1. Insulin secretion was estimated as the change in insulin divided by the change in glucose at $30 \mathrm{~min}\left(\Delta I_{0-30} /\right.$ $\left.\Delta G_{0-30}\right)$. Insulin sensitivity was estimated as $1 /$ fasting insulin. The disposition index $\left(\mathrm{DI}_{\mathrm{O}}\right)$ was calculated as $\Delta I_{0-30} / \Delta G_{0-30} X 1 /$ fasting insulin. Unpaired Student's $t$ test was used in analysis.

Han Chinese younger than Caucasians $(24.8 \pm 1.3 \mathrm{HC}$ vs. $45.3 \pm 3.8 \mathrm{C}$ years, $P<0.01)$; there was no difference in BMI $\left(25.1 \pm 1.7 \mathrm{HC}\right.$ vs. $\left.28.3 \pm 0.7 \mathrm{C} \mathrm{kg} / \mathrm{m}^{2}\right)$. There were no differences in fasting glucose $(5.4 \pm 0.1 \mathrm{HC}$ vs. $5.7 \pm 0.2 \mathrm{C}, \mathrm{mmol} / \mathrm{L}, P=0.10)$ or glycemic response to ID glucose. Fasting ( $4.9 \pm 0.8 \mathrm{HC}$ vs. $19.2 \pm 3.9 \mathrm{C}, \mathrm{mU} / \mathrm{L}$, $P<0.01)$ and $\mathrm{AUC}_{0-120} \quad(13,234 \pm 2,134 \quad \mathrm{HC}$ vs. $43,133 \pm 12,197 \mathrm{C}, \mathrm{mU} / \mathrm{L}$ min, $P=0.01)$ insulin and insulin secretion $(15.5 \pm 5.2 \mathrm{HC}$ vs. $63.2 \pm 22 \mathrm{C}$, $P=0.02$ ) were lower in Han Chinese. The $\mathrm{DI}_{\mathrm{O}}$ was not different $(2.9 \pm 0.4 \mathrm{HC}$ vs. $3.5 \pm 1.3 \mathrm{C}, P=0.63)$. Fasting $(16.2 \pm 1.3 \mathrm{HC}$ vs. $22 \pm 2.9 \mathrm{C}, \mathrm{pmol} / \mathrm{L}, P=0.06)$ and $\mathrm{AUC}_{0-120}(5,836 \pm 337 \mathrm{HC}$ vs. $7,975 \pm 739 \mathrm{C}$, pmol/ L min, $P=0.01)$ GIP were lower in Han Chinese. There was no difference in fasting $(25 \pm 3.3 \mathrm{HC}$ vs. $19.8 \pm 2.4 \mathrm{C}$, pmol/L, $P=0.24$ ) or glucose-stimulated GLP-1 (Fig. 1).

Our study indicates that, in response to intraduodenal glucose infusion, insulin secretion is less and insulin sensitivity is greater in Han Chinese than in Caucasians, associated with reduced GIP, but comparable GLP-1, secretion and $\mathrm{DI}_{\mathrm{O}}$ - the latter reflecting increased insulin sensitivity in Han Chinese. Few studies have evaluated GIP and GLP-1 responses within East Asian populations. In the only direct comparison [3], healthy Japanese were reported 
Fig. 1 Blood glucose (a), plasma insulin (b), GIP (c) and GLP-1 (d) concentrations at baseline and in response to a 120-min intraduodenal glucose infusion at $4 \mathrm{kcal} / \mathrm{min}$ in $\mathrm{Han}$ Chinese (Filled circles with bold line) and Caucasian (Empty circles with dotted line) subjects. Data are mean \pm SEM
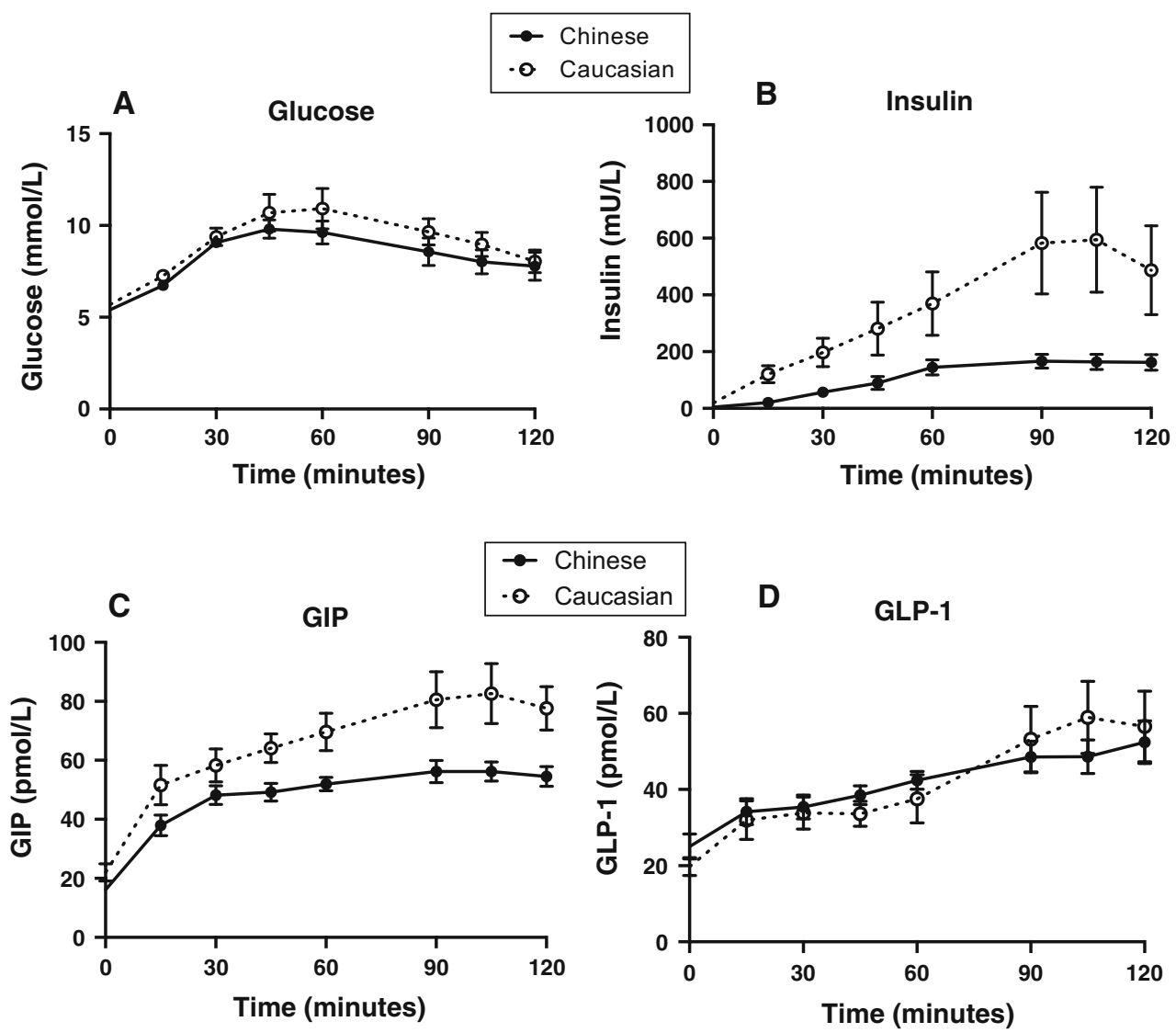

to have higher GIP and lower GLP-1 than Caucasians, but methodological limitations preclude meaningful interpretation. The reduced GIP response we observed could contribute to the diminished insulin response. In type 2 diabetes, the insulinotropic capacity of GIP is markedly reduced, and the reduction in GIP is likely to be of primary relevance to 'health.'

Limitations of our study are that the cohort was of small size and exclusively male, that responses to intraduodenal, rather than oral, glucose were evaluated and that there was a difference in age between the groups, although GIP (and GLP-1) response is apparently unaffected by age [4]. Mean BMI was higher in the Caucasians, albeit non-significantly, which may represent a confounder, although it appears that body weight does not affect the GIP response to nutrients [5].

Acknowledgments The study was supported by a grant awarded by the National Health and Medical Research Council (NHMRC) of Australia. Professor Jones' salary is provided by a NHMRC Senior Career Development Award Fellowship.

Conflict of interest The authors declare they have no conflict of interest.

Ethical standard The study protocol conformed to the principles of the Declaration of Helsinki, and was approved by the Royal Adelaide Hospital Research Ethics Committee.
Human and animal rights disclosure All procedures were in accordance with the ethical standards of the responsible committee on human experimentation (institutional and national) and with the Helsinki Declaration of 1975, as revised in 2008 [5].

Informed consent disclosure Informed consent was obtained from all patients for being included in the study.

Open Access This article is distributed under the terms of the Creative Commons Attribution License which permits any use, distribution, and reproduction in any medium, provided the original author(s) and the source are credited.

\section{References}

1. Matsumoto K, Miyake S, Yano M, Ueki Y, Yamaguchi Y, Akazawa $S$ et al (1997) Glucose tolerance, insulin secretion, and insulin sensitivity in nonobese and obese Japanese subjects. Diabetes Care 20(10):1562-1568

2. Marathe CS, Rayner CK, Bound M, Checklin H, Standfield S, Wishart J et al (2014) Small intestinal glucose exposure determines the magnitude of the incretin effect in health and type 2 diabetes. Diabetes

3. Seino Y, Fukushima M, Yabe D (2010) GIP and GLP-1, the two incretin hormones: similarities and differences. J Diabetes Investig $1(1-2): 8-23$

4. Trahair LG, Horowitz M, Rayner CK, Gentilcore D, Lange K, Wishart JM et al (2012) Comparative effects of variations in duodenal glucose load on glycemic, insulinemic, and incretin 
responses in healthy young and older subjects. J Clin Endocrinol Metab 97(3):844-851

5. Wu T, Ma J, Bound MJ, Checklin H, Deacon CF, Jones KL et al (2014) Effects of sitagliptin on glycemia, incretin hormones, and antropyloroduodenal motility in response to intraduodenal glucose infusion in healthy lean and obese humans and patients with type 2 diabetes treated with or without metformin. Diabetes 63(8): 2776-2787 